\title{
Introduction
}

\author{
Shekhar Saxena
}

The country profiles section of International Psychiatry aims to inform readers of mental health experiences and experiments from around the world. We welcome potential contributors. Please contact Shekhar Saxena (email:

saxenas@who.int).

Coordinator, Mental Health: Evidence and Research, World Health Organization, Geneva, Switzerland, email: saxenas@who.int

- his issue of International Psychiatry presents three country profiles, from Iran, Lithuania and Australia. The one from Iran traces the care of people with a mental illness through history and summarises the current mental health services and training in the country. The experience of Iran illustrates how basic mental health services can be provided to a population with the scarce resources that are available in a developing country. The profile from Lithuania shows how the availability of professionals and resources does not by itself translate into effective services in the absence of an adequate and progressive policy framework. The profile from Australia, on the other hand, provides a contrasting picture: of the provision of optimal care with a high level of resources available. This profile, along with another on Australia and $\mathrm{N}$ ew Zealand on pages 19-21 of this issue, illustrates the continuing challenges of providing mental healthcare in countries with a well developed mental health system.
In the middle ages, when in the West people with a mental illness were typically punished and tortured as witches or were looked upon as being possessed, the main approach to their care in the Islamic world, including Iran, generally involved kindness and some form of counselling, combined with herbal, aroma and music therapy and custody in special asylums.

COUNTRY PROFILE

\section{Psychiatry in Iran}

\section{Majid Sadeghi, MD, ${ }^{1}$ and Gholamreza Mirsepassi, MD FRCPsych DPM ${ }^{2}$}

${ }^{1}$ Associate Professor of Psychiatry, Tehran University of Medical Sciences, School of Medicine, Department of Psychiatry, Roozbeh Hospital, Tehran, Iran, email: sadeghmj@sina.tums.ac.ir

${ }^{2}$ Vice President, Iranian Psychiatric Association

he Islamic Republic of Iran is located in the Middle East between the Caspian Sea and the Persian Gulf. Iran's total land area is $1648000 \mathrm{~km}^{2}$. Its total population in 2003 was about 68920000 (UNICEF, 2003). The population growth rate is $1.41 \%$. O f the total population, $60.4 \%$ live in urban and $39.6 \%$ in rural areas (Yasamy et al, 2001).

\section{Health indicators}

Life expectancy at birth in the year 2002 was estimated to be 66.5 years for males and 71.7 years for females (World Health $\mathrm{O}$ rganization, 2003). The mortality rate for infants (under 1 year) was 33 per 1000 live births in the year 2003 (UN ICEF, 2003). Iran has a rather young population: roughly $40 \%$ are under 15 years and only $4.5 \%$ are aged 65 years or more (Iran Centre of Statistics, 2003).

The rate of suicide is estimated to be 6.2 per 100000 per year in both males and females.

\section{History of psychiatry in Iran}

In Iran, the history of psychiatry is as old as the history of medicine. In the middle ages, when in the West people with a mental illness were typically punished and tortured as witches or were looked upon as being possessed, the main approach to their care in the Islamic world, including Iran, generally involved kindness and some form of counselling, combined with herbal, aroma and music therapy and custody in special asylums.

Rhazes (Muhammad ibn Zakariya al-Razi, 865-925) and Avicenna (Abu Ali Ibn Sina, 980-1037), two great Iranian physicians and philoso phers, in their writings described such mental disorders as melancholia, mania and delirious states. They also prescribed psychotherapy for their patients and described the effects of emotions on the cardio vascular system.

Modern psychiatry in Iran begins with the foundation of Tehran U niversity in 1934. In 1937 the department of psychiatry at the medical school began teaching students. The first teachers at the department were mainly French-educated, among them the late Professor Abdolhossein Mirsepassi and Professor Hossein Rezai, who were pioneers of psychiatry in Iran.

There had been some asylums for the custo dy of psychiatric patients since the 19th century in Tehran and other major cities of Iran; these were mainly managed by the municipalities, and were mostly in an unfavourable condition. Roozbeh Hospital was founded in 1946 as the first modern psychiatric teaching hospital in Iran. This hospital has since trained many generations of 
psychiatrists and still is the leading centre in psychiatric education, treatment and research (Kermani, 1966).

\section{Prevalence of psychiatric disorders}

Vario us studies have estimated the point prevalence of all psychiatric disorders to be in a range from $11.9 \%$ (Bash \& Bash-Liechti, 1969) to 41.1\% (Motamedi et al, 1998). In a recent study about a fifth of interviewees ( $25.9 \%$ of the women and $14.9 \%$ of the men) were rated as likely 'cases'. Symptoms of depression and anxiety were more prevalent than somatisation and social dysfunction. The rates of learning disability, epilepsy and psychosis were $1.4 \%, 1.2 \%$ and $0.6 \%$, respectively (N oorbala et al, 2004).

\section{Substance misuse in Iran}

0 pium and its natural and synthetic components (especially heroin) are the most widely used substances in Iran, although other substances, notably cannabis, amphetamine-like drugs and to a lesser extent cocaine, seem to be used increasingly, especially by adolescents.

An estimated $2.8 \%$ of the Iranian population over the age of 15 years used opiates in 2001 (International $\mathrm{N}$ arcotics Control Strategy, 2003).

0 ne study found that $93 \%$ of o piate addicts in Iran were male, with a mean age of 33.6 years, and $1.4 \%$ were HIV positive (Yasamy et al, 2001).

Methadone maintenance and HIV prevention programmes are expanding, although HIV infection in the prison population is a serious problem (Hashemi M ohammad Abad \& London, 2003).

\section{Healthcare beliefs}

Despite a significant decrease in discrimination and stigmatisation in recent years, it seems that attitudes tow ards mental health remain a major challenge in Iran. In a recent (unpublished) study of the families of 300 patients with schizophrenia, major depressive disorder and bipolar disorder, $49 \%, 30 \%$ and $51 \%$ of these respective groups reported stigma and humiliation (further details from the first author on request).

As in many other developing countries, emotional problems are frequently expressed in somatic form. Beliefs that illness may be caused by a person with the 'evil eye' (i.e. who can harm others merely by looking at them) or an imbalance in 'hot/cold' temperaments or foods are common and coexist with more medical concepts (Sadeghi, 2003).

In general, there is less verbalisation of emotions, especially depression and anxiety. Feelings of guilt are seldom expressed spontaneously. Hypochondriasis and somatic complaints are frequent (Sarto rius et al, 1983).

Traditional healers still have a major role. 0 ne study fo und that $16 \%$ of patients had visited traditional healers and used alternative medicine before their first psychiatric visit (0 midvari et al, 2001).

\section{Mental health facilities}

There are currently 8950 psychiatric beds distributed among 23 psychiatric and general hospitals, and 825 psychiatrists are practising throughout the country, of whom 30 are child psychiatrists ( $N$ ational Research Centre of M edical Sciences, 2003; M inistry of H ealth and Medical Education, 2003).

The therapeutic modalities in Iran are mainly pharmacotherapy (the most widely used), psychotherapy and electroconvulsive therapy (ECT). Although many newer psychotherapeutic drugs are available in Iran they are generally too expensive for the average patient. Psychiatric rehabilitation facilities in general are scanty and insufficient.

\section{Psychiatric non-governmental organisations in Iran}

The Iranian Psychiatric Association was founded in 1966 and is a member of the World Psychiatric Association (W PA). The Child and Adolescent Psychiatric Association was founded in 2001.

There are also other non-governmental organisations (N GO s) active in mental heath, including the Asso ciation for the Support of Schizophrenic Patients and $\mathrm{N}$ arcotic Anonymous (N A), a self-support group for ex-addicts.

\section{Education}

\section{Undergraduate}

The duration of general medical training in Iran is 6-7 years. Medical students have a 1-month course in psychiatry, which covers theoretical aspects, and a 1-month internship during which psychiatric history taking and interviewing skills are taught.

\section{Postgraduate}

Postgraduate psychiatric training is a 3-year course covering the theoretical and practical aspects of psychiatry, including in-patient and out-patient adult psychiatry, psychiatric emergencies, psychotherapy (especially cognitive-behavioural and/or analytical approaches), consultation-liaison psychiatry, child psychiatry and rotations in forensic psychiatry and neurology. Every psychiatric resident has to conduct a supervised research project during his/her training as a prerequisite for participation in written and oral board certification examinations set by the $\mathrm{N}$ ational Board Examiners' Committee.

The only sub-specialty training is child and adolescent psychiatry, which is a 2-year course.

\section{Research}

The publication of papers in international journals has seen considerable growth during recent years: from about four in 1973 to more than 90 in 2001. However, because none of the 23 mental health journals published
Opium and its natural and synthetic components (especially heroin) are the most widely used substances in Iran.
As in many other developing countries, emotional problems are frequently expressed in somatic form.


in Iran are indexed in international databases, the output of Iranian researchers in branches of medicine related to mental health is less than may appear to be the case.

\section{Mental health promotion and policies}

The N ational Programme of M ental Health, which seeks to integrate mental healthcare within primary healthcare, was started in 1989 as a pilot study in two rural areas (Yasamy \& Bagheri Yazdi, 2004). In 1995 it was jointly evaluated by the World $\mathrm{H}$ ealth $\mathrm{O}$ rganization and the Tehran Psychiatric Institute. The programme was recognised as one the most successful in the region (Murthy, 2002).

The aim is to establish a hierarchical, pyramid-like At the base of the pyramid there are health workers known as Behvarz, who are mainly local residents of each primary healthcare area; they are trained to recognise, refer and follow

\section{psychiatric cases \\ to the higher}

level, which

comprises rural health centres.

\section{Non-biological treatments are not extensively available, being mainly limited to four or five major cities in the country.}

referral system. At the base of the pyramid there are health workers known as Behvarz, who are mainly local residents of each primary healthcare area; they are trained to recognise, refer and follow psychiatric cases to the higher level, which comprises rural health centres (Fenton, 1998). C urrently, $21.7 \%$ of the urban population and $82.8 \%$ of the rural population is covered by the $\mathrm{N}$ ational Programme of Mental $\mathrm{H}$ ealth (Yasamy et al, 2001).

\section{Future of psychiatry in Iran (opportunities and threats)}

The advancement of psychiatric education and the promotion of mental health policies in the past decade have profoundly affected psychiatric services. At present, it seems that there are enough psychiatrists in major cities throughout the country, and most psychotropic medications are available in Iran. All psychiatric hospitals are equipped with modern ECT machines.

O $n$ the other hand, non-biological treatments are not extensively available, being mainly limited to four or five major cities in the country. Iran lacks a practical and comprehensive mental health act. Limited coverage of mental health expenses by insurance companies has affected psychiatric care in both the private and the governmental sectors. D espite a dramatic increase in recent years, the mental health budget still remains highly insufficient. The Mental Health Bureau of the Ministry of Health and the Iranian Psychiatric Association have been struggling to increase the budget.

\section{References}

Bash, K. W. \& Bash-Liechti, J. (1969) Studies on the epidemiology of neuropsychiatric disorders among the population of Shiraz, Iran. Social Psychiatry, 9, 163-171.

Fenton, W. S. (1998) In M ental Health in Our Future Cities (eds D. Goldberg \& G. Thornicroft). Maudsley Monograph 42. Philadelphia, PA: Psychology Press.

Hashemi Mohammad Abad, N. \& London, M. (2003) Psychiatric practice in Iran and the UK. Psychiatric Bulletin, 27, 190-191.

International $\mathrm{N}$ arcotics Control Strategy (2003) Report released by the Bureau for International $\mathrm{N}$ arcotics and Law Enforcement Affairs.

Iran Centre of Statistics (2003) Annual Report. Tehran: Iran Centre of Statistics.

Kermani, E. J. (1966) Psychiatry in Iran. American Journal of Psychiatry, 122, 949-952.

Ministry of Health and Medical Education (2003) Statistics on Psychiatric Beds in Iran. Tehran: Ministry of Health and Medical Education.

Motamedi, S. H., Yasami, M., Karbasi, H., et al (1998) Determination of the prevalence of mental illnesses in two rural areas of Kerman. Journal of the Kerman University of Medical Sciences, 5, 31-36.

Murthy, R. S. (2002) Mental health in the Islamic Republic of Iran. Andishe Va Raftar, 7 (suppl. 4), 40-57.

$\mathrm{N}$ ational Research Centre of Medical Sciences (2003) Statistics on Psychiatric Beds in Iran. Tehran: National Research Centre of Medical Sciences.

N oorbala, A., Bagheri Yazdi, S. A., Yasamy, M. T., et al (2004) Mental health survey of the adult population in Iran. British Journal of Psychiatry, 184, 70-73.

O midvari, S., Bina, M. \& Yassemi, M. T. (2001) Pre-hospitalization pathways among psychiatric patients in Imam Hussain Hospital in 1999. Andishe Va Raftar, 6, 4-12.

Sadeghi, M. (2003) Iran. In Handbook of Cultural Health Assessment (ed. C. D'Avanzo). St Louis, MO: C. V. Mosby.

Sartorius, N., Davidian, H., Emberg, G., et al (1983) Depressive Disorders in Different Cultures. Report on the WHO Collaborative Study on Standardized Assessment of Depressive Disorders. Geneva: World Health O rganization.

UNICEF (2003) At a Glance: Iran (Islamic Republic of) Statistics. N ew York: UN ICEF.

World Health O rganization (2003) The World Health Report, Country Profiles, Iran (Islamic Republic of). Geneva: WHO.

Yasamy, M. T. \& Bagheri Yazdi, S. A. (2004) National Programme of Mental Health. Tehran: Ministry of Health and Medical Education.

Yasamy, M. T., Shahmohammadi, D., Bagheri Yazdi, S. A., et al (2001) Mental health in the Islamic Republic of Iran: achievements and areas of need. Eastern Mediterranean Health Journal, 7, 381-389.

\section{Mental health in Lithuania}

\section{Dainius Puras}

Department of Psychiatry, Vilnius University, email: dainius.puras@mf.vu.It

ithuania is a country with an approximate area of $65000 \mathrm{~km}^{2}$. Its population is 3.422 million, and the gender ratio (expressed as men per 100 women) is 87 . The proportion of the population under the age of 15 years is $18 \%$, and the proportion above the age of 60 years is $20 \%$. The literacy rate is $99.6 \%$ for both men and women. The country is in the higher middle-income group (by World Bank 2004 criteria).

The health budget represents $6 \%$ of the country's gross domestic product. The per capita total expenditure on health is $\$ 478$ (international \$) and the 